\title{
Influence of Alkaline Treatment with Ammonia Water on the Properties of PEDOT: PSS Films
}

\author{
Jiao Li, Hua Zhang, Juncheng Liu, and Hui Qi \\ School of Materials Science and Engineering, Shandong University of Technology, Zibo 255049, China \\ Correspondence should be addressed to Jiao Li, zbjli2012@163.com \\ Received 5 February 2012; Accepted 15 May 2012 \\ Academic Editor: Xie Quan
}

Copyright () 2012 Jiao Li et al. This is an open access article distributed under the Creative Commons Attribution License, which permits unrestricted use, distribution, and reproduction in any medium, provided the original work is properly cited.

A study on the influence of alkaline treatment on the properties of poly(3,4-ethylenedioxythiophene):poly(4-styrenesulfonate) (PEDOT: PSS) film is presented in this paper. The treatment is carried out using ammonia water (AW) solutions with various volumes. We have also examined the performance of organic solar cells (OSCs) with the undoped and AW-doped PEDOT:PSS layers. Results show that the acidity of PEDOT:PSS solution can be significantly reduced by adding the AW solution with the optimized volume ratio $\leq 9 \%$, v/v, while the AW-doped PEDOT:PSS film shows an improved optical transmission and stabilized conductivity. However, compared to the pristine OSC without adding AW to the whole-extraction layer, the AW-doped OSC shows a slight degradation in the power conversion efficiency (from $2.12 \%$ to $2.02 \%$ ), which has been attributed to the decreased $V_{\text {oc }}$ and FF of devices after the addition of AW.

\section{Introduction}

Over the last years, poly(3,4-ethylenedioxythiophene): poly (4-styrenesulfonate) (PEDOT:PSS) has emerged as a promising material for the electrodes in optoelectronic devices. It proved many advantages over other conducting polymers, such as a high transparency in the near-infrared, excellent thermal stability, and compatibility in aqueous solution [ 1 , 2]. Consequently, it has been widely applied as a buffer layer for electrodes in organic electronics. For example, it was reported to be an efficient hole-extracting layer between the ITO and active layers in organic solar cells (OSCs) [35]. However, the primary disadvantage of PEDOT:PSS film is its acidity, which is believed to etch the surface of ITO liberating oxygen and metal ions, which contaminate the adjacent photoactive organic layer to the detriment of the device performance [6-8].

Recent studies have been carried out to investigate the replacement of PEDOT:PSS by a more suitable material, such as acid-carbon nanotubes [9], $\mathrm{NiO}$ [10], and SWCNTsporphyrin [11]. However, the performances of OSCs with these replacements are lower than those of the device with the hole-extraction layer of PEDOT:PSS. According to the acidbase theory, the acidity of a solution can be neutralized by adding the alkaline solution. To the best of our knowledge, the use of an alkaline solution to reduce the acidity of PEDOT:PSS has hardly been reported, thus this could be considered as an alternative approach to achieve better film properties.

In this work, the PEDOT:PSS doped with different content ammonia water transparent conducting films is fabricated on quartz substrates by the spin coating method. We report the influence of alkaline treatment on the properties of PEDOT:PSS films. In addition, we study the performance of polymer solar cells with the undoped and doped PEDOT:PSS layer.

\section{Experimental}

PEDOT:PSS aqueous solution ( $1.3 \mathrm{wt} \%$ dispersed in $\mathrm{H}_{2} \mathrm{O}$ ) from Aldrich (as supplied) was filtered with a $0.45 \mu \mathrm{m}$ polyvinyl difluoride (PVDF) syringe filter. Ammonia water (AW, analytical grade), used as a dopant, was purchased from Aldrich (as supplied). Other reagents and solvents were of analytical grade.

Molecular structure of PEDOT:PSS and schematic structure of PEDOT doped PSS are shown in Figure 1. In the 


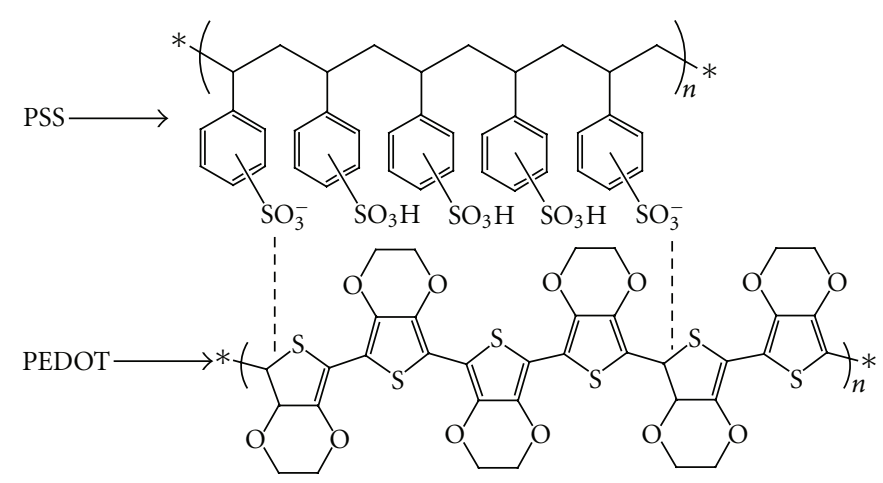

(a)

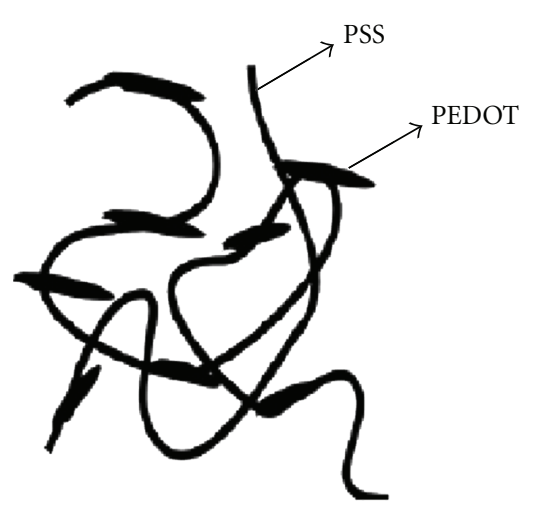

(b)

FIGURE 1: Molecular structure of PEDOT:PSS (a) and schematic structure of PEDOT doped PSS (b) [12].

PEDOT:PSS dispersion, as a conducting polymer, PEDOT is the charge transporting species $[13,14]$. PSS serves as a charge-compensating counterion to stabilize the $p$-doped conducting polymer and forms a processable waterborne dispersion of negatively charged swollen colloidal particles consisting of PEDOT and excess PSS [14, 15]. Since PSS chains typically consist of a few hundred monomer units, the polymer grains are presumably defined by the PSS random coil with PEDOT chains ironically attached along them [12] as shown in Figure 1(b).

All the quartz substrates $(20 \mathrm{~mm} \times 20 \mathrm{~mm})$ were ultrasonically purified by a series of organic solvents (ethanol, methanol, and acetone), then rinsed in an ultrasonic bath with deionized water, and dried in a vacuum oven. Residual organic contaminations were subsequently removed upon exposure to a UV-ozone lamp for $30 \mathrm{~min}$. Prior to spincoating, a certain volume ratio of AW and PEDOT:PSS solution was prepared by addition of AW to the PEDOT:PSS aqueous dispersion in an ultrasonic bath for about 5 minutes. The PEDOT:PSS and AW-doped PEDOT:PSS films (PEDOT:PSS and A-PEDOT:PSS, resp.) with a thickness of 95-100 nm, as determined with scanning electron microscopy, were fabricated on transparent quartz substrates by the spin coating method. The spin coating procedure included $20 \mathrm{~s}$ of $2000 \mathrm{rpm}$ followed by $30 \mathrm{~s}$ of $5000 \mathrm{rmp}$. Then, these films were dried at $120^{\circ}$ for $20 \mathrm{~min}$ in the vacuum oven before any further characterization.

The devices in this work were fabricated using indiumtin-oxide- (ITO-) coated glass substrates $(<10$ ohms per square). The treatment process of ITO substrate was the same as the quartz substrate. Solution of AW and PEDOT:PSS was spin-coated on top of the ITO surface to form a buffer layer $(90-100 \mathrm{~nm})$ before drying the substrates at $120^{\circ} \mathrm{C}$ in an oven for $20 \mathrm{~min}$. The $\mathrm{P}_{3} \mathrm{HT}$ : PCBM was dissolved in dichlorobenzene with a weight ratio of $1: 0.8$ and stirred for more than $72 \mathrm{~h}$ in the glove box before spin casting to form the blending layer. Finally, an $\mathrm{Al}$ electrode with about $100 \mathrm{~nm}$ in thickness was deposited by thermal evaporation at a pressure of $2.4 \times 10^{-4} \mathrm{~Pa}$ through a shadow mask. The basic structure of the organic photovoltaics (OPV) devices is shown in Figure 2.

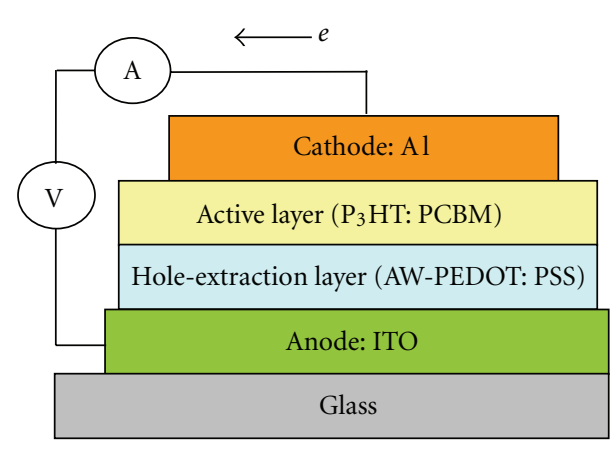

FIGURE 2: Schematic device structure for organic solar cells doped with AW.

The $\mathrm{pH}$ of the solution was measured by the PHS-3C $\mathrm{pH}$ meter. The conductivity of the films was determined by the four-point probe technique with a Keithley 2400 Source Meter. The optical property of the composite films was characterized with a TU-1901 Dual-beam UVVisible spectrophotometer. Current density-voltage $(I-V)$ characteristics of the OPV cells were measured by using a computer-controlled Keithley 2400 Source Meter under a simulated light intensity of $100 \mathrm{~mW} / \mathrm{cm}^{2}$ (AM $1.5 \mathrm{G}$ ), which was calibrated by an optical power meter from a halogen lamp. The power conversion efficiency (PCE) was calculated from the $I-V$ characteristics. The devices were tested in the air without encapsulation, and all the measurements were performed at room temperature.

\section{Results and Discussion}

We have investigated the acidity of PEDOT:PSS solutions doped with different AW contents. As shown in Figure 3, the $\mathrm{pH}$ of commercially available PEDOT:PSS solution is about 1.51, while its $\mathrm{pH}$ value increases in a two-stage variation with an increase of the AW doping ratio. Initially, it was observed that the $\mathrm{pH}$ is increased slowly as the AW doping ratio increases from $0 \%(\mathrm{v} / \mathrm{v})$ to $9 \%(\mathrm{v} / \mathrm{v})$, while, increases drastically with the AW doping ratio improvement from $9 \%$ 


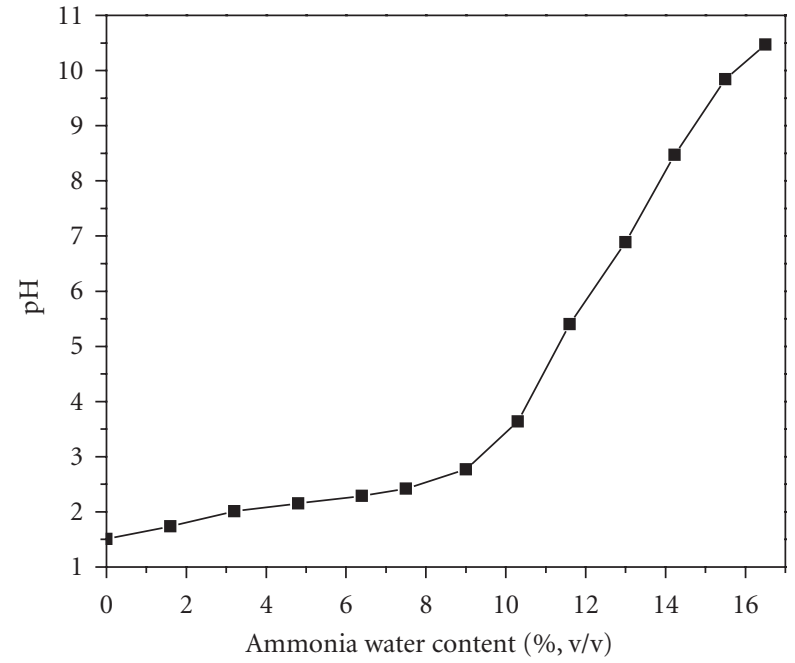

FIgUre 3: The $\mathrm{pH}$ of PEDOT:PSS solutions with different AW doping ratios.

$(\mathrm{v} / \mathrm{v})$ to $16.5 \%(\mathrm{v} / \mathrm{v})$. The $\mathrm{pH}$ of composite solution is nearly neutral (6.96) with the AW doping ratio about 13\% (v/v). This indicates that the acidity of PEDOT:PSS solution can be remarkably reduced by AW fillings.

The plots of the electrical conductivity as a function of AW content at room temperature are shown in Figure 4. Upon increasing the AW doping ratio, the conductivity of AW-doped films initially keeps constant and then decreases. When AW content reaches about $16.5 \%(\mathrm{v} / \mathrm{v})$, the conductivity of doped film reduces to $0.09 \mathrm{~S} / \mathrm{cm}$, lesser about $67.8 \%$ than that of pure PEDOT:PSS film $(0.28 \mathrm{~S} / \mathrm{cm})$. This result indicates that the addition of AW up to $9 \%(\mathrm{v} / \mathrm{v})$ has no effect on the conductivity of doped films, while the alkalinity of AW-PEDOT:PSS solution with the addition of more amounts of AW leads to the decrease of the conductivity of films. The $p$-doped PEDOT chain may be dedoped in basic environments. It results in changes in their electronic states and thereby leads to the decrease in the film conductivity $[14,16]$.

As shown in Figure 5, the optical transmittance of PEDOT:PSS films modified with different AW doping ratios slightly increase up in the wavelength range from $600 \mathrm{~nm}$ to $800 \mathrm{~nm}$, which corresponds to the power density of ambient sunlight on the Earth surface [17]. In particular, the pronounced increase is observed in the wavelengths between 700 and $800 \mathrm{~nm}$. This indicates that the added AW might affect the interaction between PEDOT and $\mathrm{PSS}^{-}$. The better optical property of PEDOT:PSS layer is conducive to increase the absorption of light and the generation of excitons within the active region of the solar cell, which is of great benefit to improve the OSCs performance $[17,18]$.

Figure 6 shows the current density-voltage curves of photovoltaic cells with undoped and AW-doped PEDOT:PSS films as the hole-extraction layer of devices. The detailed parameters of devices are summarized in Table 1.

As shown in Table 1, there is an obvious decrease in the open circuit voltage $\left(V_{\mathrm{oc}}\right)$ with the increase in the AW

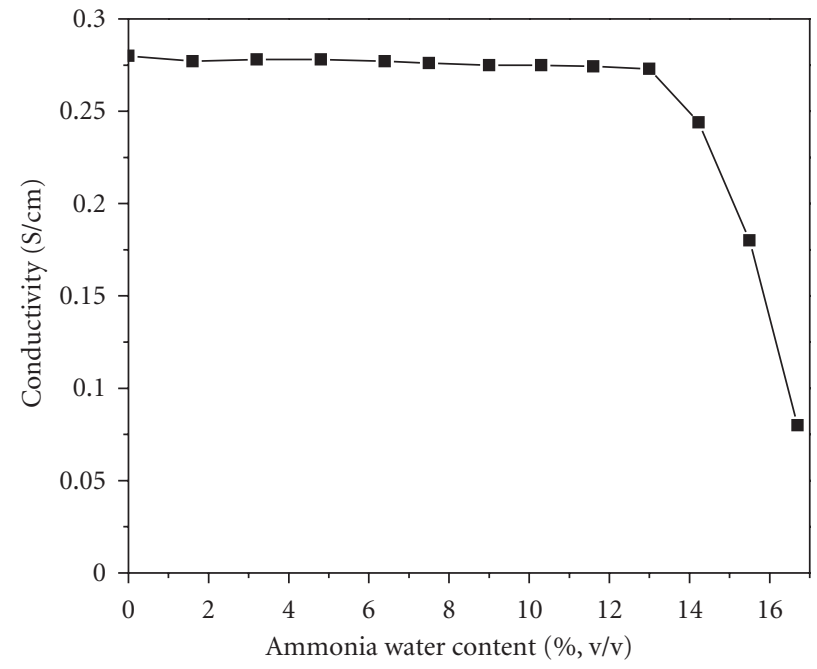

FIgure 4: The electrical conductivity of PEDOT:PSS films as a function of doping ratio of AW.

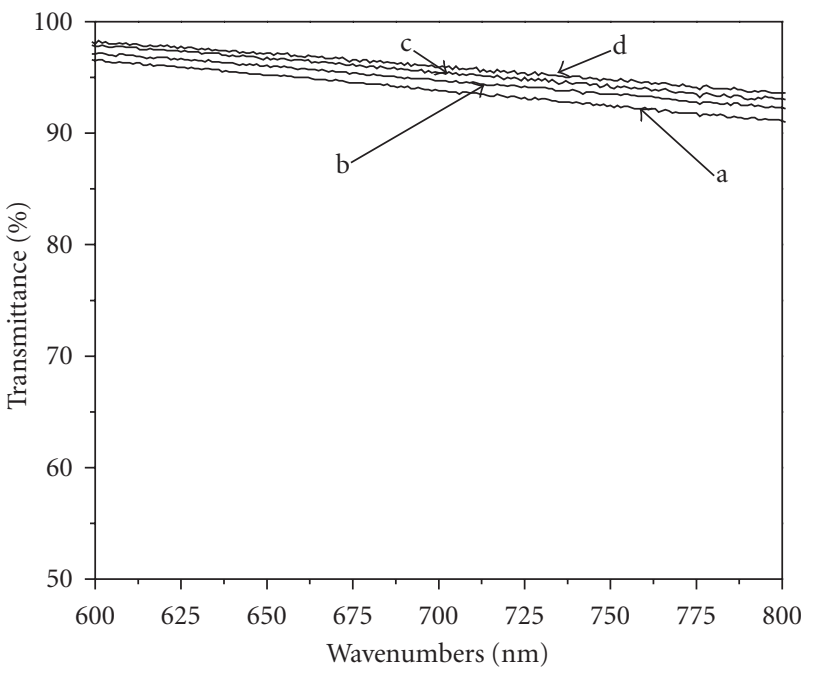

(a) Pure PEDOT: PSS film

(c) A (13\%,v/v)-PEDOT: PSS film

(b) A (9\%,v/v)-PEDOT: PSS film

(d) A (16.5\%, v/v)-PEDOT: PSS film

FIgure 5: The optical transmittance of PEDOT:PSS films as a function of doping ratio of AW.

amount. $V_{\text {oc }}$ of the OPV cell is limited by the work function of the electrodes or the buffer layers, that is, it is determined by the work function of PEDOT:PSS films [19, 20]. For this reason, it can be concluded that a decrease in $V_{\mathrm{oc}}$ with the addition of AW is mainly a result of deterioration in modifying the work function of the PEDOT:PSS film. Meanwhile, it was reported that the content of $\mathrm{PSS}^{-}$of PEDOT:PSS films played an important role in the work function of the PEDOT:PSS film [21]. Here, the addition of AW into PEDOT:PSS may bring more effect on the $\mathrm{PSS}^{-}$. It may lead to a low work function of the hole-extraction layer compared to undoped PEDOT:PSS film and has an effect on 
TABLE 1: PV parameters of OPVs for AW doping.

\begin{tabular}{|c|c|c|c|c|c|c|}
\hline Style & Structure & $\mathrm{pH}$ & $V_{\mathrm{oc}}(\mathrm{V})$ & $I_{\mathrm{sc}}\left(\mathrm{mA} / \mathrm{cm}^{2}\right)$ & $F F(\%)$ & $\eta(\%)$ \\
\hline A & ITO/PEDOT $:$ PSS/P ${ }_{3} \mathrm{HT}: \mathrm{PCBM} / \mathrm{Al}$ & 1.51 & 0.56 & 8.82 & 43.0 & $2.12 \%$ \\
\hline B & ITO/A (9\%)-PEDOT : PSS/P ${ }_{3} \mathrm{HT}: \mathrm{PCBM} / \mathrm{Al}$ & 2.77 & 0.54 & 8.98 & 42.8 & $2.08 \%$ \\
\hline $\mathrm{C}$ & ITO/A (13\%)-PEDOT : PSS/P 3 HT : PCBM/Al & 6.96 & 0.52 & 9.14 & 42.5 & $2.02 \%$ \\
\hline $\mathrm{D}$ & ITO/A (16.5\%)-PEDOT: PSS/P ${ }_{3} \mathrm{HT}: \mathrm{PCBM} / \mathrm{Al}$ & 10.45 & 0.42 & 5.15 & 34.0 & $0.74 \%$ \\
\hline
\end{tabular}

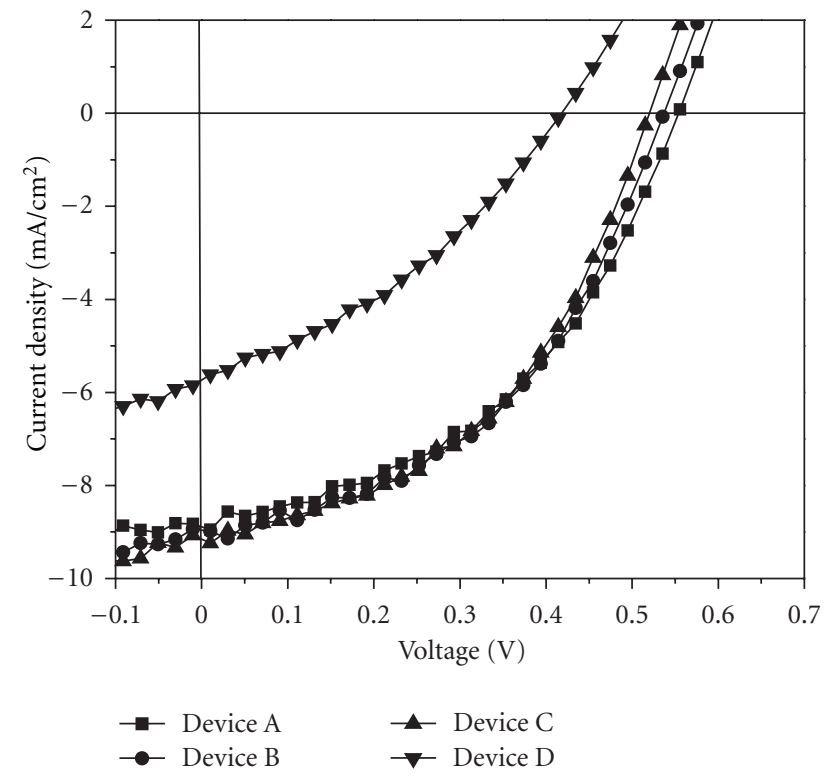

FIgURE 6: The $I-V$ characteristics of devices with different contents of AW. Device A: pristine PEDOT:PSS film; Device B: A (9\%, v/v)PEDOT:PSS film. device C: A (13\%, v/v)-PEDOT: PSS film; device D: A (16.5\%, v/v)-PEDOT:PSS film.

$V_{\text {oc }}$ of the PV cell. However, this is still an assumption and needs to be further studied.

Table 1 also shows the increase in the short circuit current $\left(I_{\mathrm{sc}}\right)$ from about $8.82 \mathrm{~mA} / \mathrm{cm}^{2}$ of the reference device A $(0 \%, \mathrm{v} / \mathrm{v})$ to $9.14 \mathrm{~mA} / \mathrm{cm}^{2}$ of device C $(13 \%, \mathrm{v} / \mathrm{v})$, and after that the $I_{\mathrm{sc}}$ decreases to become $5.15 \mathrm{~mA} / \mathrm{cm}^{2}$ of device $\mathrm{D}$ $(16.5 \%, v / v)$. Since these devices are fabricated with the same materials and the same procedure and the only difference is the hole-extraction layer, the increased current is unlikely on account of other reasons. Moreover, compared with undoped films, doped films $(\leq 9 \%, \mathrm{v} / \mathrm{v})$ show a more stable conductivity and a slight increase in optical transmittance in the wavelength range from $600 \mathrm{~nm}$ to $800 \mathrm{~nm}$ (as shown in Figures 4 and 5). Therefore, the increased current is mainly due to the high optical transmittance of the hole-extraction layers leading to a higher photon absorption yield and the charge carrier transport yield within the active region of the device [20]. More hole carriers in the $\mathrm{P}_{3} \mathrm{HT} / \mathrm{PCBM}$ active layer move into the anode through the PEDOT:PSS film. However the decrease in $I_{\mathrm{sc}}$ with addition of more amounts of AW may lead to the decrease of the conductivity of doped films $(\geq 9 \%, v / v)$, which has effects on the series resistance of OVP cell.
The change of $V_{\mathrm{oc}}$ and $I_{\mathrm{sc}}$ with increased AW content is also responsible for the fill factor (FF) and power conversion efficiency of OSC. The device with the doped hole-extraction layer $(\leq 9 \%, v / v)$ showed a lowered FF (42.5), and the performance of the device was slightly degraded $(2.02 \%)$.

\section{Conclusion}

In summary, we have fabricated a series of PEDOT:PSS films by inclusion of different contents of AW into aqueous PEDOT:PSS solution and investigated the influence of alkali treatment on the PEDOT:PSS solution acidity and the optical and electrical properties of PEDOT:PSS films. We also examined the performance of OSCs with the un-doped and AW-doped PEDOT:PSS layers. Results show that the acidity of PEDOT:PSS solution can be remarkably reduced by adding the AW solution with the optimized volume ratio $(\leq 9 \%, v / v)$, while the $A W$-doped PEDOT:PSS film shows an improvement in the optical transmission and stabilized conductivity. However, compared to the pristine OSC without adding AW to the hole-extraction layer, the AW-doped OSC shows a slight degradation in the power conversion efficiency (from $2.12 \%$ to $2.02 \%$ ), which has been attributed to the decreased $V_{\text {oc }}$ and FF of devices after the addition of AW.

\section{Acknowledgments}

Financial support from the program for Natural Science Foundation of Shandong Province (no. ZR2011EL033) is acknowledged. The authors also thank the Fund for Scientific Research Foundation from Shangdong University of Technology (no. 410010).

\section{References}

[1] G. Heywang and F. Jonas, "Poly(alkylenedioxythiophene)snew, very stable conducting polymers," Advanced Materials, vol. 4, no. 2, pp. 116-118, 1992.

[2] L. Groenendaal, F. Jonas, D. Freitag, H. Pielartzik, and J. R. Reynolds, "Poly(3,4-ethylenedioxythiophene) and its derivatives: past, present, and future," Advanced Materials, vol. 12, no. 7, pp. 481-494, 2000.

[3] S. Park, S. J. Tark, and D. Kim, "Effect of sorbitol doping in PEDOT:PSS on the electrical performance of organic photovoltaic devices," Current Applied Physics, vol. 11, no. 4, pp. 1299-1301, 2011.

[4] K. X. Steirer, M. O. Reese, B. L. Rupert et al., "Ultrasonic spray deposition for production of organic solar cells," Solar Energy Materials and Solar Cells, vol. 93, no. 4, pp. 447-453, 2009. 
[5] J. Liu, J. Li, C. Gao, and G. Chen, "Nanocomposite holeextraction layers for organic solar cells," International Journal of Photoenergy, vol. 2011, Article ID 392832, 5 pages, 2011.

[6] M. P. de Jong, L. J. van Ijzendoorn, and M. J. A. de Voigt, "Stability of the interface between indium-tin-oxide and poly $(3,4$ ethylenedioxythiophene)/poly(styrenesulfonate) in polymer light-emitting diodes," Applied Physics Letters, vol. 77, no. 14, pp. 2255-2257, 2000.

[7] K. W. Wong, H. L. Yip, Y. Luo et al., "Blocking reactions between indium-tin oxide and poly (3,4-ethylene dioxythiophene):poly(styrene sulphonate) with a self-assembly monolayer," Applied Physics Letters, vol. 80, no. 15, pp. 2788-2790, 2002.

[8] T. P. Nguyen and S. A. De Vos, "An investigation into the effect of chemical and thermal treatments on the structural changes of poly(3,4-ethylenedioxythiophene)/polystyrenesulfonate and consequences on its use on indium tin oxide substrates," Applied Surface Science, vol. 221, no. 1-4, pp. 330-339, 2004.

[9] R. A. Hatton, N. P. Blanchard, L. W. Tan, G. Latini, F. Cacialli, and S. R. P. Silva, "Oxidised carbon nanotubes as solution processable, high work function hole-extraction layers for organic solar cells," Organic Electronics, vol. 10, no. 3, pp. 388395, 2009 .

[10] M. D. Irwin, D. B. Buchholz, A. W. Hains, R. P. H. Chang, and T. J. Marks, "p-Type semiconducting nickel oxide as an efficiency-enhancing anode interfacial layer in polymer bulk-heterojunction solar cells," Proceedings of the National Academy of Sciences of the United States of America, vol. 105, no. 8, pp. 2783-2787, 2008.

[11] T. Hasobe, S. Fukuzumi, and P. V. Kamat, "Organized assemblies of single wall carbon nanotubes and porphyrin for photochemical solar cells: Charge injection from excited porphyrin into single-walled carbon nanotubes," Journal of Physical Chemistry B, vol. 110, no. 50, pp. 25477-25484, 2006.

[12] Y. Yang, Y. Jiang, J. Xu, and J. Yu, "Conducting PEDOT-PSS composite films assembled by LB technique," Colloids and Surfaces A, vol. 302, no. 1-3, pp. 157-161, 2007.

[13] S. K. M. Jönsson, J. Birgerson, X. Crispin et al., "The effects of solvents on the morphology and sheet resistance in poly $(3,4-$ ethylenedioxythiophene)-polystyrenesulfonic acid (PEDOTPSS) films," Synthetic Metals, vol. 139, no. 1, pp. 1-10, 2003.

[14] O. P. Dimitriev, Y. P. Piryatinski, and A. A. Pud, "Evidence of the controlled interaction between PEDOT and PSS in the PEDOT:PSS complex via concentration changes of the complex solution," Journal of Physical Chemistry B, vol. 115, no. 6, pp. 1357-1362, 2011.

[15] S. Ghosh and O. Inganäs, "Self-assembly of a conducting polymer nanostructure by physical crosslinking: applications to conducting blends and modified electrodes," Synthetic Metals, vol. 101, no. 1-3, pp. 413-416, 1999.

[16] S. Garreau, G. Louarn, J. P. Buisson, G. Froyer, and S. Lefrant, "In situ spectroelectrochemical Raman studies of poly $(3,4-$ ethylenedioxythiophene) (PEDT)," Macromolecules, vol. 32, no. 20, pp. 6807-6812, 1999.

[17] B. R. Saunders and M. L. Turner, "Nanoparticle-polymer photovoltaic cells," Advances in Colloid and Interface Science, vol. 138, no. 1, pp. 1-23, 2008.

[18] S. R. Forrest, "The limits to organic photovoltaic cell efficiency," MRS Bulletin, vol. 30, no. 1, pp. 28-32, 2005.

[19] F. L. Zhang, A. Gadisa, O. Inganäs, M. Svensson, and M. R. Andersson, "Influence of buffer layers on the performance of polymer solar cells," Applied Physics Letters, vol. 84, no. 19, pp. 3906-3908, 2004.
[20] Y. W. Li, P. Y. Liu, L. T. Hou, and B. Wu, "Heterojunction organic solar cells with Rubrene as electron transporting layer," Wuli Xuebao/Acta Physica Sinica, vol. 59, no. 2, pp. 1248-1251, 2010 (Chinese).

[21] J. Hwang, F. Amy, and A. Kahn, "Spectroscopic study on sputtered PEDOT · PSS: role of surface PSS layer," Organic Electronics, vol. 7, no. 5, pp. 387-396, 2006. 


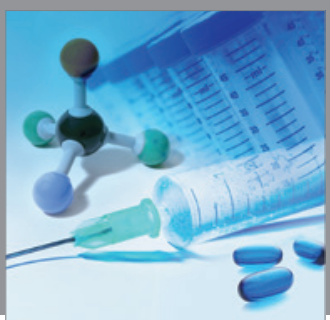

International Journal of

Medicinal Chemistry

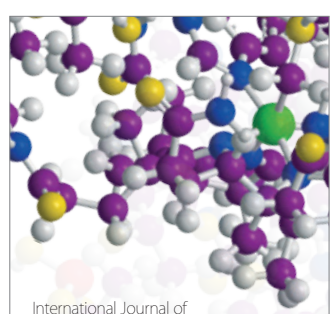

Carbohydrate Chemistry

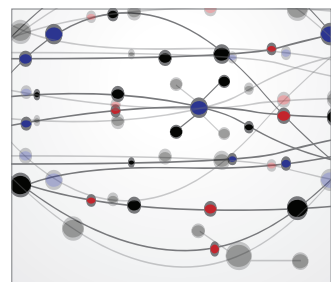

The Scientific World Journal
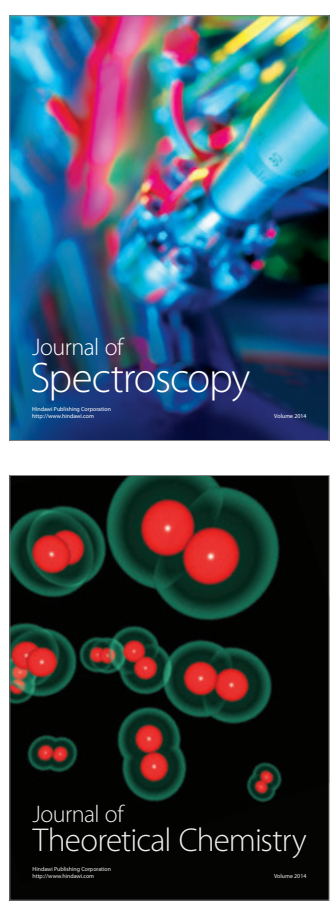
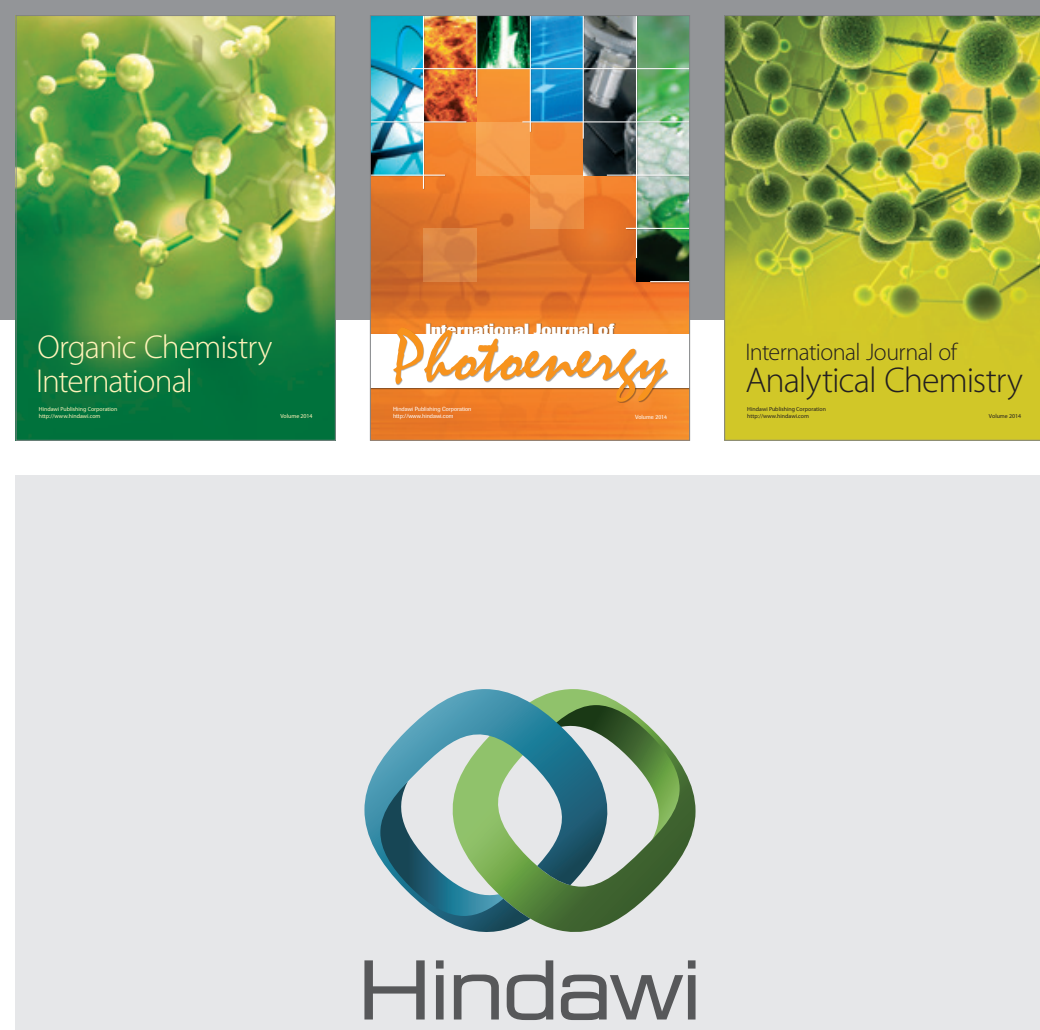

Submit your manuscripts at

http://www.hindawi.com
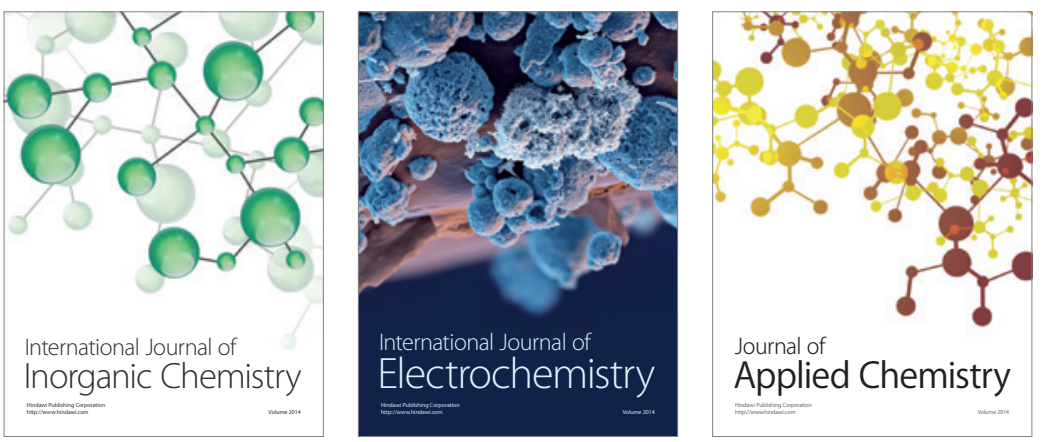

Journal of

Applied Chemistry
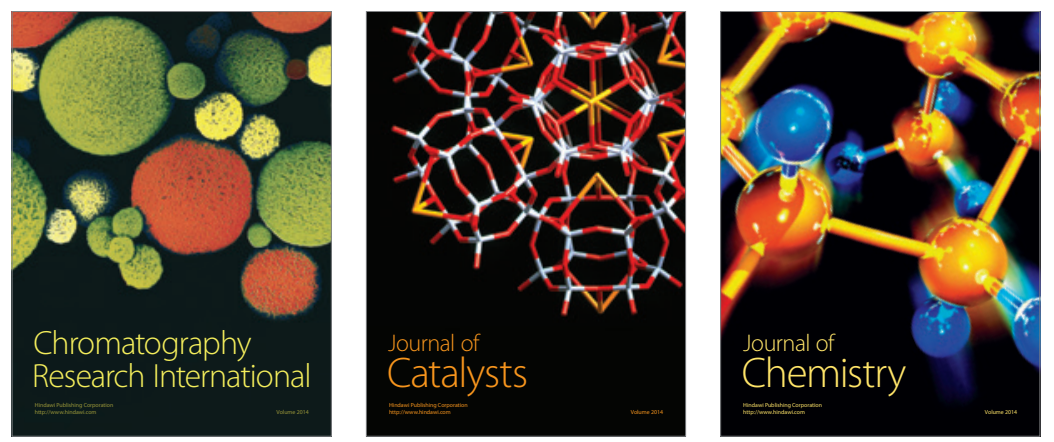
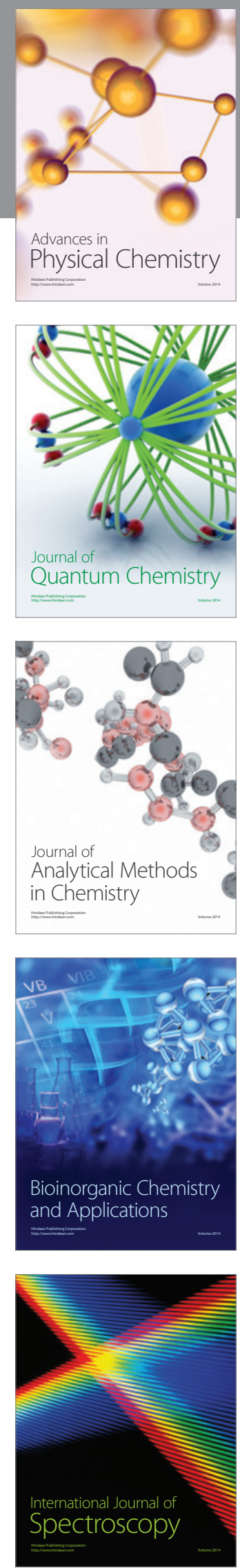